\title{
Antirid peptides in cosmeceutical formula
}

\author{
Gabriela TATARINGA, Ana Maria ZBANCIOC \\ Faculty of Pharmacy, "Grigore T. Popa" University of Medicine and Pharmacy, Iasi, Romania
}

\begin{abstract}
Perception of beauty is tied to the idea of youth. This is why a large number of peptides proposed in the field of cosmetics are used as anti-aging/anti-wrinkle products. Some peptides have been proven in their efficacy through clinical skin trials. This paper describes some peptides that are most frequently used in cosmeceutical products and their potential benefits and practical use in dermatology.
\end{abstract}

Keywords: signal peptides, neurotransmitter peptides inhibitors, carrier peptides

\section{GENERAL CONSIDERATIONS}

Peptides entered the cosmeceutical field long time ago, when Loren Pickart proposed the synthetic peptide GHK as a signal peptide enhancing collagen production and acting as a carrier peptide when complexed with copper (II) [1]. It was the first copper peptide incorporated into skin care products [2]. Since then, because of their versatility, a multitude of peptides with cosmeceutical interest have been developed in response to the most frequent and not fully satisfied market requests [3].

Peptides are short polymers formed by binding in a certain order, a several $\alpha$-amino acids. The bond between two amino acids is called the peptide bond. Peptides are differentiated from proteins according to the number of amino acids they contain; a peptide is defined by the FDA as a polymer composed of less than 40 amino acids (500-5000 Da) [4]. The shortest peptides contain two amino acids in their structure is called dipeptides. Proteins consist of one or more polypeptides arranged in a biologically functional manner [5].

\section{CHARACTERISTICS OF PEPTIDES AND PROTEINS USED IN COSMETIC PREPARATIONS}

Pharmaceutical companies frequently use peptides as active ingredients in their creams. Peptides have different effects on the skin, especially for cosmetic purposes, but an important problem in their topical use is their low ability to penetrate the skin [6].

In general, the ability of a substance to penetrate the skin depends on several factors such as: physicochemical properties of the substance (dissociation constant, molecular weight, stability, binding capacity, solubility and partition coefficient); integrity, thickness and constituent components of the skin; skin metabolism; the duration and the area on which it is applied; the properties of the transdermal device and creating a local repository at the application site [7].

Topically administered peptides and proteins are used extensively. Peptides and proteins commonly used for cosmetic purposes, depending on the mechanism of action, have been classified into four groups: signal peptides, enzyme inhibitory peptides, 
neurotransmitter inhibitory peptides and carrier peptides [8].

\section{Signal peptides}

Signal peptides generally stimulate matrix-producing proteins and specifically stimulate collagen synthesis. They can be achieved by stimulating and growing different types of skin cells such as human skin fibroblasts. Signal peptides may also increase the production of elastin, proteoglycan, glucosaminoglycans and the proliferation of fibronectin [9].

By increasing the activity of the stem cell and consequently the production of collagen, the skin looks firmer and younger.

Natural aging of the skin results from decreased production and increased degradation of extracellular matrix proteins such as collagen, fibronectin, elastin and laminin. The extracellular matrix, in addition to providing structural support, also influences cellular behavior such as differentiation and proliferation.

\section{Collagen modulating peptides}

Palmitoyl-pentapeptide (Pal-KTTKS) is a synthesis signal peptide from a pro-collagen I fragment. It stimulates collagen I, III and VI and fibronectin, elastin and glucosaminoglycan production and has been frequently used as an anti-wrinkle and anti-aging topical agent (Fig. 1) [10]. This peptide contains 5 amino acids joined by an aliphatic chain with 16 carbon atoms and has the role of improving the permeability of the molecule through the lipid structure of the skin [8].

Palmitoyl tripeptide-1 (Pal-GHK, Pal-tripeptide 1) is a synthetic peptide consists of a short chain of 3 amino acids (also known as GHK peptide [a fragment of type

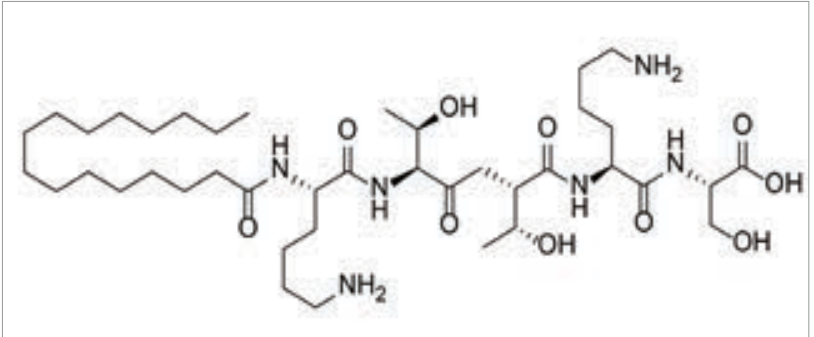

FIGURE 1. Chemical structure of Pal-KTTKS (Palmitoyl-pentapeptide)

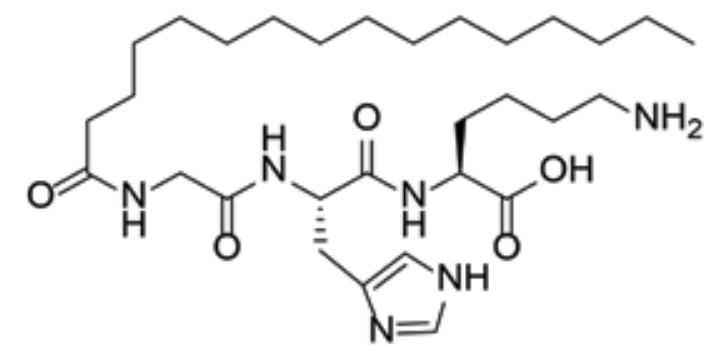

FIGURE 2. Chemical structure of Pal-GHK (Pal-tripeptide 1)

I collagen] or glycine-histidine-lysine) connected via an amide bond at its $\mathrm{N}$-terminus to palmitic acid (Fig. 2). In vitro and in vivo studies have shown that Pal-GHK stimulates the synthesis of collagen and glycosaminoglycans. It is frequently used in cosmetics for their anti-aging, anti-wrinkle, firming and moisturizing action.

Palmitoyl tripeptide- $3 / 5$ is a small tripeptide mimics thrombospondin I tripeptide sequence and promotes collagen formation; is a synthetic signal-peptide that mimics the action of thrombospondin that causes the Arg-Phe-Lys sequence to bind to the inactive form of $\beta$-growth factor and which further induces the release of the growth factor- $\beta$ into the active form (Fig. 3).

In cosmetic preparations this peptide is used as a firming agent, as a skin moisturizing agent, as an anti-wrinkle agent, but also in order to improve the appearance of stretch marks [8].

Tripeptide-10 Citrulline is a peptide with firmness effects. It also regulates collagen fibrillogenesis and influences diameter and placement of collagen fibres [11]. It is a peptide with anti-aging properties, but it is also a good firming and sun protection agent (Fig. 4).

Acetyl-tetrapeptide-9 (AcTP1) and Acetyltetrapeptide-11 (AcTP2) are synthetic signal proteins;

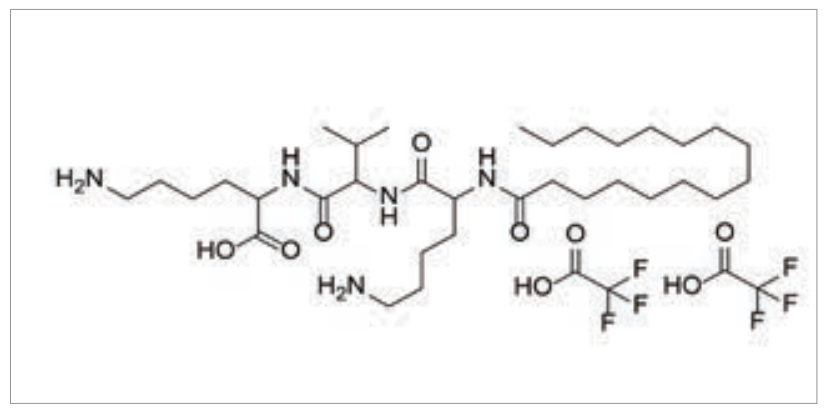

FIGURE 3. Chemical structure of Palmitoyl tripeptide-3/5 


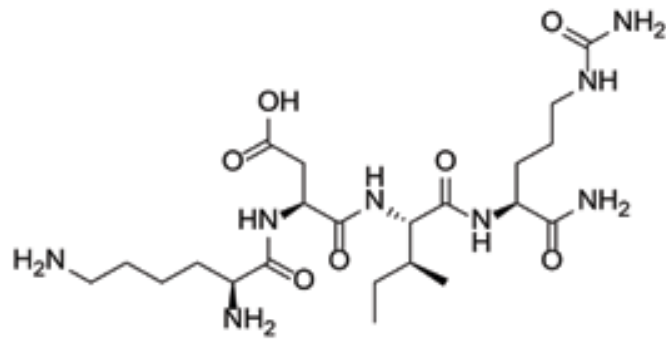

FIGURE 4. Chemical structure of Tripeptide-10 Citrulline

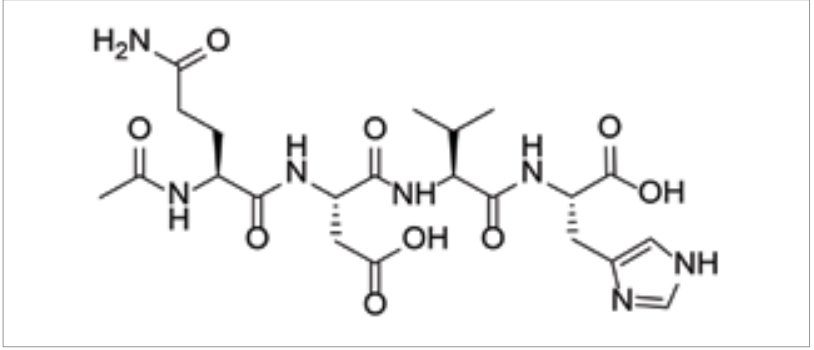

FIGURE 5. Chemical structure of AcTP1

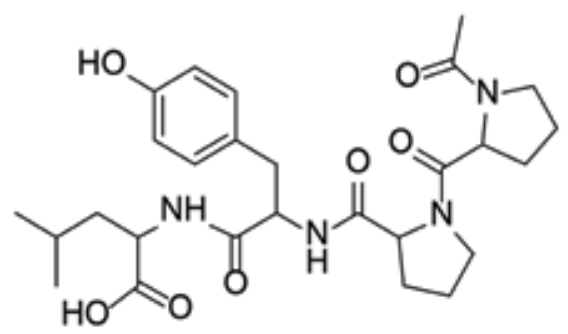

FIGURE 6. Chemical structure of AcTP2

AcTP1stimulates collagen I and lumican synthesis and AcTP2 stimulates keratinocyte cell growth and syndecan-1 synthesis (Fig. 5, Fig. 6) [12].

A recent study showed the effectiveness of acetyl tetrapeptide- 9 on parameters such as: skin hydration (improved by $46.9 \%$ ), skin elasticity was significantly improved (by 8.9\%) after application for 6 weeks. There was also a significant decrease in the severity of the skin (9.3\%) [13].

\section{Elastin modulating peptides}

Elastic fibers are important components of the extracellular matrix and are composed of two elements: microfibers and matrix elastin. Natural aging but also exposure to ultraviolet radiation cause degenerative changes in the structure of elastic fibers.

Valine-glycine-valine-alanine-proline-glycine (VGVAPG) is a hexapeptide that has high specificity for the

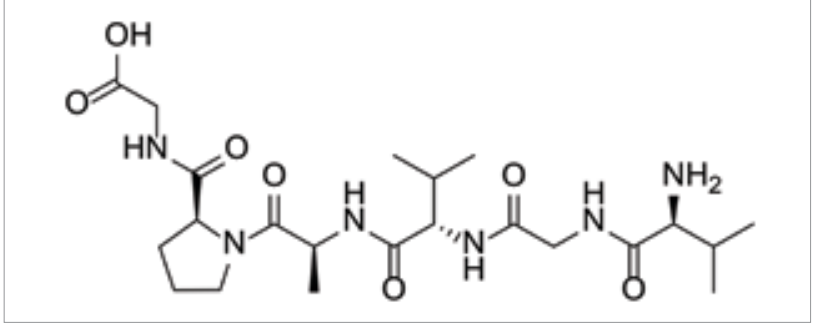

FIGURE 7. Chemical structure of VGVAPG<smiles>CSCC[C@H](NC(=O)[C@H](CCC(=O)O)NC(=O)[C@H](CCC(=O)O)NC(C)=O)C(=O)N[C@@H](CCC(N)=O)C(=O)N[C@@H](CCCNC(=N)N)C(=O)N[C@@H](CCCNC(=N)N)C(N)=O</smiles>

FIGURE 8. Chemical structure of Ac-Glu-Glu-Met-Gln-Arg-Arg-NH2

elastin molecule and is involved in the self-regulation of elastin synthesis by a negative feedback mechanism (Fig. 7). VGVAPG not only stimulates the synthesis of collagen but also decreases the synthesis of elastin [14]. It is also a potent stimulator of fibroblasts in human skin and is incorporated into cosmetics to provide dermal reconstruction and to produce chemotaxis for restructuring and repair [15].

\section{Neurotransmitter peptides inhibitors}

Neurotransmitter peptides inhibitors are the most recent cosmeceutical peptides; these inhibit the release of acetylcholine at the neuromuscular junction and have a similar effect (curara-like effect) to tubocurarine.

Acetyl-glutamyl-glutamyl-methoxil-glutaminyl-arginylarginylamide (Argireline, Ac-Glu-Glu-Met-Gln-Arg-Arg$\mathrm{NH} 2$ ) inhibits the release of neurotransmitters as it interferes with the formation and stabilization of the protein complex needed for docking vesicles of acetylcholine release. This is a synthetic peptide that is mainly used as a component of eye care products and modeled from $\mathrm{N}$-terminal SNAP- 25 protein that inhibits SNARE complex formation and catecholamine release (Fig. 8). Inhibition of norepinephrine and adrenaline release has also been demonstrated. 


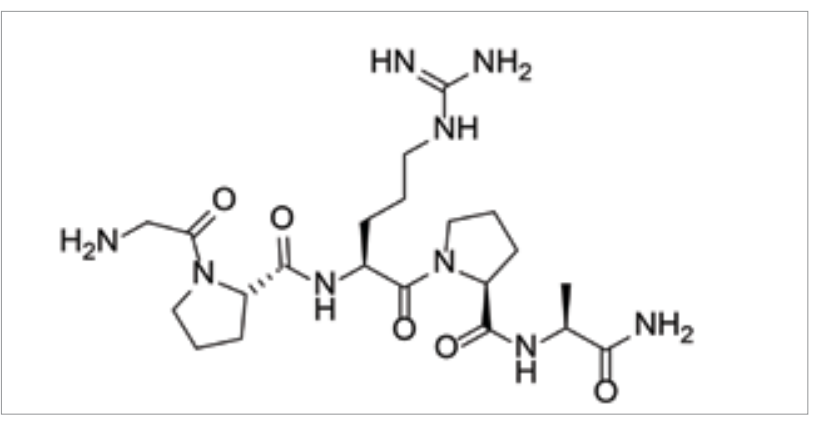

FIGURE 9. Chemical structure of Pentapeptide-3

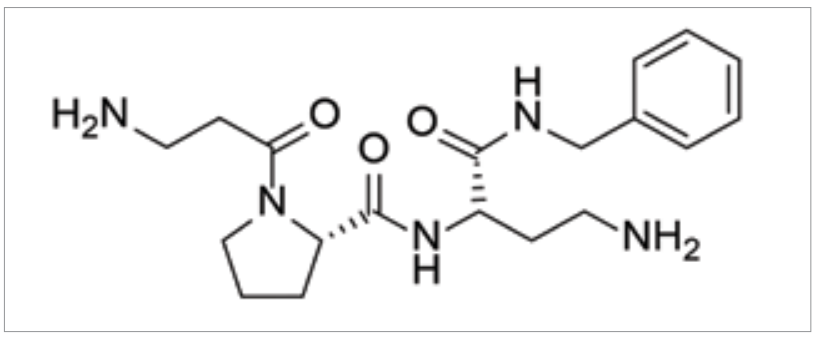

FIGURE 10. Chemical structure of Tripeptide-3

This peptide is frequently used in cosmetics for its anti-wrinkle properties, especially in the periorbital area, as a skin moisturizer and as a toning and firming agent [16].

Pentapeptide-3 (Vialox), a synthetic peptide that is a competitive antagonist at the acetylcholine receptors, inhibits depolarization and blocks the sodium ions release at the synaptic membrane of muscles so that they will not contract as frequently (Fig. 9) (8). In vitro tests showed a $71 \%$ reduction in muscle contractions 1 minute after treatment and $58 \%$ after 2 hours. Uncommon muscle contractions result in more superficial lines. After 28 days of use twice a day, the depth of wrinkles was reduced by $49 \%$ [17].

In cosmetics, Pentapeptide- 3 is used for its antiwrinkle and anti-aging properties [15].

Tripeptide-3 (Syn-Ake, beta-Ala-Pro-Dab-NH-benzyl) is used as an anti-wrinkle agent. This active tri-peptide acts in a manner similar to Waglerin 1 , a neuromuscular blocking compound of the venom of the Temple Viper. It has been developed as efficient smoothing and anti-wrinkle care particularly effective against expression lines by relaxing facial muscles [8].

Tripeptide- 3 causes reversible antagonism of muscle nicotinic acetylcholine receptors in the post-synaptic membrane, preventing acetylcholine binding to receptors [18].
In a study of 45 healthy subjects, Syn-Ake, Argireline and placebo were compared. Syn-Ake has certainly demonstrated greater efficacy for all parameters tested [15].

Different formulations containing Tripeptide- 3 are available on the market: face creams, serums, and eye patches [19].

\section{Carrier peptides}

Carrier peptides belong to a general category that acts as a mediator of the transport of an important substance, but their major application is to deliver important trace elements (such as $\mathrm{Cu}$ and $\mathrm{Mn}$ ), which are necessary for wound healing and enzymatic processes [14]. Recently, several peptides and proteins have been developed to accelerate and facilitate the distribution of bioactive molecules into the skin. These peptides and proteins are known as penetrating peptides or as membrane transduction peptides and have basic transduction sphere in their structure.

The first carrier peptides marketed were designed to transport $\mathrm{Cu}$, a necessary element for wound healing, in damaged tissue. Metals are very difficult to transport and are unstable in various pharmaceutical forms, but the use of carrier peptides has been shown to be effective [20]. Thus, the first carrier peptide used and that has been most widely studied is GHK (GlycylL-histidyl-L-lysine). It was isolated from human plasma and then synthesized in the laboratory.

The binding of GHK to copper, abbreviated GHK-Cu (Fig. 11), led to a compound used in wound healing creams and was then adapted for a line of cosmetics to minimize the appearance of fine lines and wrinkles [21].

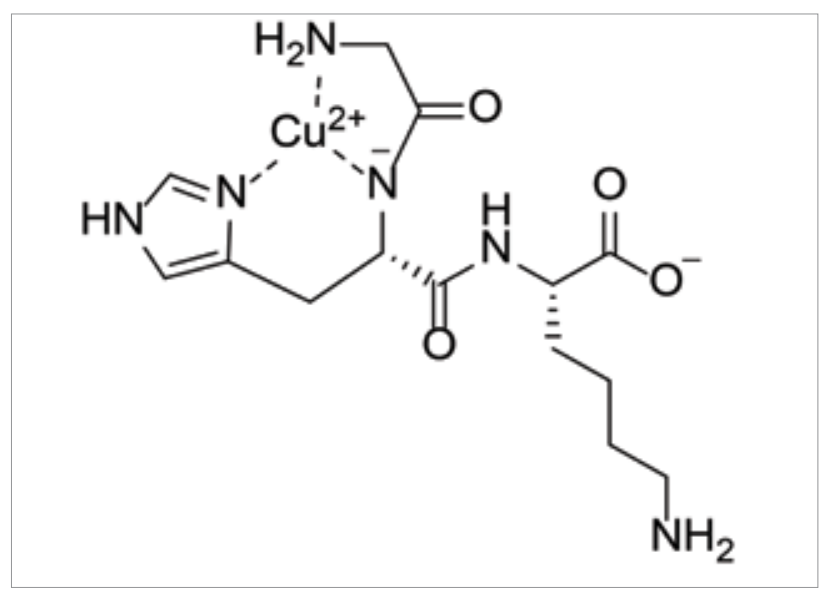

FIGURE 11. Chemical structure of GHK-Cu 
Copper plays an important role in the enzymatic reactions associated with the wound healing process. It is a co-factor of lysyl oxidase and superoxide dismutase that are involved in the production of collagen and the prevention of free radical damage. Studies have shown that the tripeptide glycyl-histidyllysine, a fragment of the alpha chain of collagen, has an increased affinity for copper ions and forms a GHK-Cu complex with it [22].

GHK-Cu was tested in a 12-week, placebo-controlled study of 71 women with mild to advanced ultraviolet radiation problems. After the first week, the active cream showed a significant improvement in skin laxity, clarity and overall appearance when compared to placebo. Significant improvements were seen in the second week for thin, fine wrinkles and for wrinkles in the fourth week compared to placebo. The elastic properties have been significantly improved. Subjects indicated increased cream acceptability. There were no side effects or irritation [23].

The efficacy and safety of GHK-Cu was investigated in the periorbital area in 41 female volunteers with skin to skin problems caused by moderate to advanced ultraviolet radiation. Within 4 weeks of starting this study with Vitamin $\mathrm{K}$ cream as a comparison group, an improvement was observed in all parameters, including fine lines, wrinkles and the entire appearance of the eyelids. The elastic properties of the skin in the periorbital area showed an improvement from the first week. An increase in skin density and thickness was demonstrated with ultrasound and digital imaging, which showed an improvement in the skin in the periorbital area [24].

\section{CONCLUSIONS}

Any cosmetic products which contain bioactive peptides in their formulations must be submitted to efficacy and safety tests. Together, some peptides show notable effects on skin that is aged or affected by ultraviolet radiation. However, there is a large gap in the permeability coefficient of many peptides and proteins used in cosmetics, which is why researchers should focus on this ambiguity and find more effective substances with much better permeability. The paper also shows that there is still a lot of work required, and a lot of additional research to perform.

The analysis of the recent literature data shows an increasing number of scientific studies of bioactive peptides used as ingredients in different cosmeceutical products. Due to the vast functionality of peptides, there is growing research on bioactive peptides aimed at investigating their uses in products developed for stimulating collagen and elastin synthesis and improving skin healing.

\section{REFERENCES}

1. Pickart $L$, Thaler MM. Tripeptide in human serum which prolongs survival of normal liver cells and stimulates growth in neoplastic liver. Nat New Biol. 1973;243:85-87.

2. Schagen SK. Topical Peptide Treatments with Effective AntiAging Results. Cosmetics 2017; 4(16): 4020016 (1-14).

3. Errante F, Ledwon P, Latajka R et al. Cosmeceutical Peptides in the Framework of Sustainable Wellness Economy. Front. Chem. 2020; 8: 572923.

4. Cooper B, legre J, O'Donovan D et al. Spring Peptides as a platform for targeted therapeutics for cancer: peptide-drug conjugates (PDCs). Chem. Soc. Rev. 2021; 50: 1480-1494.

5. Hongzhong W, Chunyan R, Fang Y et al. Extraction and identification of collagen-derived peptides with hematopoietic activity from CollaCoriiAsini. J. Ethnopharmacol. 2016; 129-136.

6. Cullander C, Guy RH. Routes of delivery: case studies (6). Trasdermal delivery of peptides and proteins. Adv. Drug Deliv. Rev. 1992; 8: 291-329.

7. Mohammed YH, Yamada M, Lynlee L et al. Microneedle enhanced delivery of cosmeceutically relevant peptides in human skin. PLoS One 2014; 9(7): e101956 (1-9).

8. Gorouhi F, Maibach HI. Role of topical peptides in preventing or treating aged skin. Int. J. Cosmet. Sci. 2009; 327-345.
9. Schagen S. Topical peptide treatments with effective anti-aging results. Cosmetics 2017; 4:16.

10. Foldvari M, Attah-Poku S, Hu J et al. Palmitoyl derivatives of interferon alpha: potential for cutaneous delivery. J. Pharm. Sci. 1998; 87: 1203-1208.

11.Puig A, Anton JMG, Mangues M. A new decorin-like tetrapeptide for optimal organization of collagen fibres. Int J. Cosmet. Sci. 2008; 30: 97-104.

12. Pauly G, Contet-Audonneau J, Moussou P et al. Small proteoglycans in the skin: New targets in the fight against aging. IFSCC 2008; 11: 21-29.

13. Papageorgiou S, Varvaresou A, Protopapa E et al. Efficacy evaluation and stability study of a multifunctional cosmetic cream containing antioxidants, phyto-steroids and Acetyl Tetrapeptide-9. Molecules 2015; 201-204.

14. El Hadmed HH, Castillo RF. Cosmeceuticals: peptides, proteins, and growth factors. J. Cosmet. Dermatol. 2016; 15: 514-519.

15. Pai VV, Bhandari P, Shukla P. Topical peptides as cosmeceuticals. Indian J. Dermatol. VenereolLeprol. 2017; 1-5.

16. Raikou V, Varvaresou A, Panderi I et al. The efficacy study of the combination of tripeptide-10-citrulline and acetyl hexapeptide-3. 
A prospective, randomized controlled study. J. Cosmet. Dermatol. 2017; 16: 271-278.

17. Padamwar MN, Pawar AP, Daithankar AV et al. Silk sericin as a moisturizer: an in vivo study. J. Cosmetic Dermatology 2005; 250-257.

18. Reddy BY, Jow T, Hantash BM. Bioactive oligopeptides in dermatology. Exp. Dermatol. 2012; 21:569-575.

19. ${ }^{* *}$ https://www.dsm.com/personal-care/en_US/products/ skin-bioactives/syn-ake.html (accessed June 08, 2020).

20. Lupo MP, Cole AL. Cosmeceutical peptides: cosmeceutical peptides. Dermatol. Ther. 2007; 20: 343-349.

21.Snyder EL, Dowdy SF. Recent advances in the use of protein transduction domains for the delivery of peptides, proteins and nucleic acids in vivo. Expert Opin. Drug Deliv. 2005; 43-51

22. Maquart FX, Pickart L, Laurent M, et al. Stimulation of collagen synthesis in fibroblast cultures by the tripeptide-copper complex glycyl-L-histidyl-L-lysine-Cu2+. FEBS Letters 1988; 238: 343-346.

23. Pickart L, Margolina A. Regenerative and protective actions of the GHK-Cu Peptide in the light of the new gene data. Int. J. Mol. Sci. 2018; 2-8.

24. Leyden JJ, Stevens T, Finkey MB et al. Skin care benefits of copper peptide containing facial cream. In Proceedings of the American Academy of Dermatology 60th Annual Meeting, New Orleans, LA, USA, 22-27 February 2002; p. 29.

Conflict of interest: none declared Financial support: none declared 